\title{
Acidentes por escorpião Tityus sp. (scorpiones: Buthidae) em crianças: discussão de dois óbitos
}

\author{
Accidents by scorpio Tityus sp. (scorpiones: Buthidae) in children: two orbit report \\ Accidentes por scorpion Tityus sp. (scorpiones: Buthidae) en niños: discusión de dos muertes
}

Recebido: 28/01/2021 | Revisado: 02/02/2021 | Aceito: 06/02/2021 | Publicado: 14/02/2021

\author{
Mirella Machado Ortiz \\ ORCID: https://orcid.org/0000-0002-2635-3184 \\ Universidade Estadual de Maringá, Brasil \\ E-mail: mirella_mortiz@hotmail.com \\ Paola Kallyana Guarneri Carvalho de Lima \\ ORCID: https://orcid.org/0000-0001-5078-1835 \\ Universidade Estadual de Maringá, Brasil \\ E-mail: paolakgcl@gmail.com \\ Camila Cristiane Formaggi Sales \\ ORCID: https://orcid.org/0000-0002-6645-1299 \\ Universidade Estadual de Maringá, Brasil \\ E-mail: camila cfs14@hotmail.com \\ Indianathan de Kassia Santana Elvira \\ ORCID: https://orcid.org/0000-0003-4827-1523 \\ Universidade Estadual de Maringá, Brasil \\ E-mail: indianathan_19@hotmail.com \\ Aline de Oliveira Barbosa \\ ORCID: https://orcid.org/0000-0001-5914-3768 \\ Universidade Estadual de Maringá, Brasil \\ E-mail: alineotb@gmail.com \\ Karen França Rocha \\ ORCID: https://orcid.org/0000-0002-2468-7199 \\ Universidade Estadual de Maringá, Brasil \\ Email: karenrochaf2@gmail.com \\ Márcia Regina Jupi Guedes \\ ORCID: https://orcid.org/0000-0002-2480-0438 \\ Universidade Estadual de Maringá, Brasil \\ E-mail: mrjupi@yahoo.com.br \\ Sergio Ricardo Lopes de Oliveira \\ ORCID: https://orcid.org/0000-0002-6904-1244 \\ Universidade Estadual de Maringá, Brasil \\ Email: sergiolopes.uem@gmail.com \\ Magda Lúcia Félix de Oliveira \\ ORCID: https://orcid.org/0000-0003-4095-9382 \\ Universidade Estadual de Maringá, Brasil \\ E-mail:mlfoliveira@uem.br
}

\begin{abstract}
Resumo
Objetivo: descrever dois casos de acidentes infantis com escorpião da espécie Tityus serrulatus com desfecho de óbito e o tempo para a utilização de soroterapia antiescorpiônica. Metodologia: estudo descritivo e documental, na modalidade de estudo de casos múltiplos, realizado a partir de dois casos de escorpionismo infantil notificadas a um centro de informação e assistência toxicológica do Paraná, no ano de 2017. Dados coletados de fichas epidemiológicas de Acidentes por Animais Peçonhentos - Escorpião, de fichas de Visita Domiciliar e prontuários hospitalares das crianças.Resultados: encontrou-se gravidade precoce dos casos e a necessidade do uso precoce da soroterapia antiescorpiônica, da utilização de leitos de terapia intensiva e de equipes de saúde para atendimento de alta complexidade, configurando os acidentes escorpiônicos como emergências reais de saúde. Conclusão: como lições dos casos, encontraram-se aspectos positivos no atendimento, como a precocidade do acesso à unidade de saúde e a identificação dos sinais e sintomas, mas o tempo entre o acidente e a soroterapia antiescorpiônica foi acima do preconizado, determinante do desfecho dos casos.
\end{abstract}

Palavras- chave: Saúde da criança; Acidentes; Animais peçonhentos; Picadas de escorpião; Gravidade do paciente.

\section{Abstract}

Objective: to describe two cases of child accidents with scorpion of the genus Tityus serrulatus with death outcome and the duration of antiscorpionic serotherapy.Methodology:descriptive and documentary study, in the multiple case study modality, carried out from two cases of infantile scorpionism notified to an information and toxicological assistance 
center in Paraná, in 2017. Data were collected from epidemiological records of Accidents by Venomous Animals Scorpion, Home Visit records and children's medical charts.Results: early severity of the cases and the need of early serotherapy, in addition to the need of intensive care unit and health teams for high complexity care were found, setting scorpion accidents as real health emergencies.Conclusion: as lessons from the cases, positive aspects were found in care, such as the early access to the health unit and the identification of signs and symptoms, but the time between the accident and antiscorpionic serotherapy was longer than recommended, determining the outcome of the cases.

Keywords: Child health; Accidents; Animals poisonous; Scorpion stings; Patient acuity.

\section{Resumen}

Objetivo: describir dos casos de accidentes infantiles con escorpiones de la especie Tityus serrulatus con desenlace de muerte y tiempo de uso de seroterapia antiescorpiónica.Metodología: estudio descriptivo y documental, en la modalidad de estudio de casos múltiples, realizado a partir de dos casos de escorpionismo infantil notificados a un centro de información y asistencia toxicológica en Paraná, en el año 2017. Datos recolectados de registros epidemiológicos de Accidentes por Animales Venenosos - Escorpio , formularios de visitas domiciliarias y registros del hospital infantil.Resultados: hubo una gravedad temprana de los casos y la necesidad del uso temprano de seroterapia antiescorpión, el uso de camas de cuidados intensivos y equipos de salud para cuidados de alta complejidad, configurando los accidentes de escorpión como emergencias de salud reales.Conclusión: como lecciones de los casos, se encontraron aspectos positivos en la atención, como el acceso precoz a la unidad de salud y la identificación de signos y síntomas, pero el tiempo entre el accidente y la seroterapia antiescorpión fue mayor al recomendado, lo que determina el resultado. de los casos.

Palabras clave: Salud infantil; Accidentes; Animales venenosos; Picaduras de escorpión; Severidad del paciente.

\section{Introduçãa}

No Brasil, são registrados mais de 150 mil acidentes por animais peçonhentos anualmente (Santana \&, Suchara, 2015) representando a segunda causa de notificação toxicológica aos centros de informação e assistência toxicológica - CIAT (Souza et al., 2017)0. Estes acidentes são reconhecidos pela Organização Mundial da Saúde como um problema de saúde pública emergente, especialmente em países tropicais ou subtropicais, embora considerados negligenciados em políticas públicas e estejam incluídos na lista de Doenças Tropicais Negligenciadas (Who, 2007; Bochner, Fiszon, \& Machado, 2014).

Animais peçonhentos possuem glândulas de veneno com um aparato inoculador, como ferrões, aguilhões e quelíceras, porém nem todos com esta capacidade apresentam importância médica, caracterizando intoxicação, casos que se verifica um acúmulo de veneno no organismo, ocasionando danos nas células do tecido, do sangue e/ou sistema nervoso (Cardoso et al., 2003; Torrez et al., 2019). Existem 160 espécies de escorpiões catalogadas no Brasil, e três espécies do gênero Tityus são responsáveis por envenenamentos graves nas regiões Sul, Sudeste, Centro-Oeste e Nordeste, a saber: T. bahiensis (escorpião marrom), T. serrulatus (escorpião amarelo) e T. stigmurus (escorpião do nordeste) (Torrez et al., 2019).

O perfil epidemiológico do escorpionismo, considerado o quadro de envenenamento causado pela inoculação de toxinas dos escorpiões, retrata um aumento gradativo de casos nos anos de 2000 a 2017 e crescente gravidade ao longo da última década (Brasil, 2017a). Dados do Sistema de Informação de Agravos de Notificação - SINAN, indicam registros de 159 mil acidentes por animais peçonhentos no país no ano de 2015, dos quais os acidentes escorpiônicos foram os mais frequentes - 87.801 casos (55\%) (Souza et al., 2017; Brasil, 2017a).

O escorpião amarelo é considerado a espécie mais perigosa da América do Sul, sendo responsável pelos casos clínicos mais severos de envenenamento provocado por inoculação de veneno por seu ferrão ou télson (Sesa, 2016). Medindo até sete centímetros de comprimento, tem hábito urbano, com grande capacidade de adaptação ao ambiente, e migrando para se alimentar onde há abundância de baratas. As fêmeas dessa espécie conseguem se reproduzir por meio do processo partenogênese e cada ninhada pode resultar em até 30 filhotes. Atualmente, pode ser encontrado em 19 dos 27 estados brasileiros (Torrez et al., 2019).

(Figura 1) 
Figura 1. Tityus serrulatus (Buthidae).

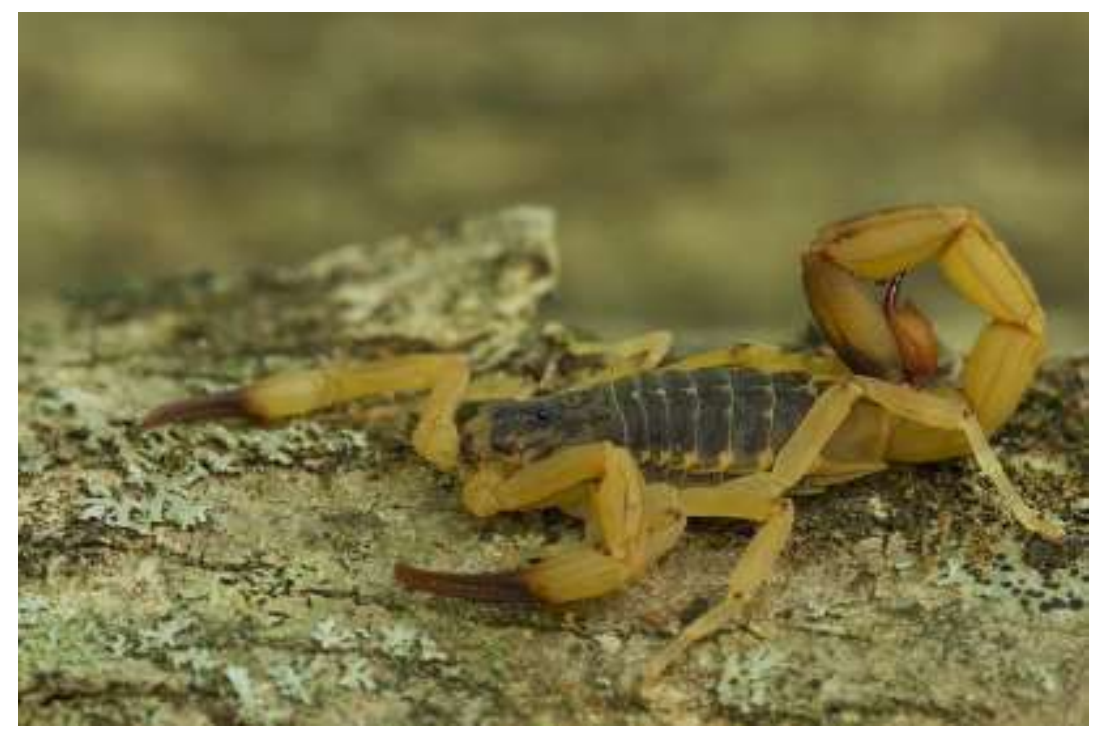

Imagem: José Roberto Peruca, 21 de novembro de 2015, Parque da Fazenda do Estado, Araçatuba/SP - Brasil. Bioma: Mata Atlântica.

https://www.flickr.com/photos/jose_roberto_peruca/22768698194

No estado do Paraná estes acidentes assumem relevância pela expansão da distribuição geográfica dos animais e pelo aumento da frequência de casos. No intervalo entre 2000 a 2017 foram notificados 15.860 casos. Somente no ano de 2017 foram 2.334 casos, com a incidência de 20,6/100.000 habitantes e dois óbitos (Brasil, 2017a). Tityus serrulatus está urbanizado no Estado do Paraná, com número expressivo de acidentes graves (Sesa, 2016).

Por ser um acidente tipicamente urbano e peridomiciliar, o escorpionismo tem relevância epidemiológica em crianças, pois a proximidade do escorpião com o domicílio torna a atividade lúdica potencialmente perigosa (Brasil, 2017b). Particularmente, crianças são mais vulneráveis e apresentam especificidades de acordo com diferentes faixas etárias, especialmente aquelas menores de cinco anos de idade, visto que apresentam imaturidade física e mental, inexperiência e incapacidade para prever situações de perigo, grande curiosidade e motivação em realizar tarefas em ambiente externo (Carmo et al., 2019; Lima, Soares, \& Pinho, 2016).

No Brasil, o escorpionismo apresenta elevados índices de letalidade em crianças (Lima et al., 2016; Mesquita et al., 2015). As crianças com manifestações clínicas de envenenamento podem necessitar de soroterapia antiveneno, de acordo com a intensidade do envenenamento, definido pelo quadro instalado, visto que o intervalo de tempo entre o acidente e o estabelecimento do tratamento tem associação direta com o prognóstico do acidente (Mesquita et al., 2015).

Estudos para discutir e analisar os casos de escorpionismo nessa fase do ciclo vital poderão contribuir no planejamento das ações de saúde por meio do direcionamento de uma assistência adequada e imediata aos grupos mais vulneráveis, assim como subsidiar o delineamento de estratégias que venham reduzir a morbimortalidade por esse agravo. Neste contexto, o objeti vo do presente trabalho foi descrever dois casos de acidentes infantis com escorpião da espécie Tityus serrulatus que levaram ao desfecho de óbito e o tempo para a utilização de soroterapia antiescorpiônica.

\section{Metodologia}

Trata-se de um estudo qualitativo, do tipo descritivo e documental, na modalidade de estudo de casos múltiplos, (Yin, 2015; Pereira et al., 2018) ocorridos em 2017, cujos dados foram coletados das fichas epidemiológicas de Acidentes por Animais Peçonhentos - AAP Escorpionismo, das fichas de visita domiciliar à família do intoxicado, arquivadas no Centro de Controle de 
Intoxicações do Hospital Universitário Regional de Maringá, Paraná - Brasil (CCI/HUM), e de registros dos prontuários hospitalares das crianças.

Considerando que as práticas de saúde estão inseridas em contextos sociais complexos, o estudo de casos múltiplos tem sido uma importante estratégia de pesquisa para investigar fenômenos relacionados à saúde por possibilitar a captação de diferentes pontos de vista, aspectos objetivos e subjetivos presentes em uma situação social e tem como vantagem proporcionar, por meio das evidências dos casos, um estudo mais sujeito às generalizações (Yin, 2015; Pereira et al., 2018).

Para seleção dos casos foi utilizada a Relação Mensal dos Pacientes Internados do CCI/HUM. Dos registros nas fichas Acidentes por Animais Peçonhentos (AAP) Escorpionismo e nos prontuários hospitalares das crianças foram compiladas informações sobre características individuais das crianças (sexo, idade, raça/cor), dos acidentes escorpiônicos (agente tóxico, município do tratamento, data do acidente, tempo decorrido entre acidente e início dos sintomas e entre o acidente e o tratamento), da história e manejo clínico (local e circunstância do acidente, história de intoxicação anterior, tratamento prévio em outro serviço, exames complementares solicitados) e evolução dos casos, que foram relatados descritivamente e analisados juntamente com revisão de literatura.

O projeto de pesquisa foi submetido ao Comitê Permanente de Ética em Pesquisa Envolvendo Seres Humanos da Universidade Estadual de Maringá, com parecer 3.227.049, com assinatura do Termo de Conssentimento Livre e Esclarecido TCLE durante a visita domiciliar. Para sigilo fos casos, foram utilizados os identificadores fictícios "agosto" e "setembro".

\section{Resultados}

Os dois casos descritos configuram acidentes escorpiônicos infantis como emergências reais de saúde e têm em comum a gravidade clínica imediata dos casos, a necessidade de utilização de local adequado para o manejo clínico e de equipes de saúde para atendimento de alta complexidade, e a necessidade do uso precoce da soroterapia antiescorpiônica - SAE.

Aspectos positivos no atendimento, como a precocidade do acesso à unidade de saúde e a identificação dos sinais e sintomas dos acidentes escorpiônicos, foram diminuídos pelo tempo entre o acidente e a SAE, imprescindível para o desfecho dos casos, que esteve acima do preconizado.

\section{Ocorrência 1 - Agosto}

Quatro anos, masculino, foi admitido em Unidade de Pronto Atendimento - UPA em município da região Noroeste do Paraná, após duas horas do acidente individual por escorpião amarelo, ocorridoàs 6h:00min, com marcas da picada na região do pescoço, inicialmente ignorada. Encontrava-se na residência, localizada em zona urbana de município de pequeno porte, onde recebeu o primeiro atendimento. Escorpião foi visualizado.

Após estadiamento de gravidade do caso, foi transferida para hospital do município de referência de área de saúde, via Serviço de Atendimento Móvel de Urgência - SAMU Rodoviário Regional, para um segundo atendimento. Profissional da unidade hospitalar realizou contato telefônico com o Centro de Informação e Assistência Toxicológica - CIAT de referência para a macrorregião Noroeste do Paraná, e solicitou conduta para o caso.

Após duas horas do acidente até o atendimento hospitalar, criança apresentava sudorese, náuseas e vômito, dispneia, baixa responsividade + rebaixamento do nível de consciência, e pontuação 8 na Escala de Coma de Glasgow. O caso foi classificado como acidente grave por escorpião amarelo - Tityus serrulatus (Benchimol \& Sá, 2007), e orientado a realização do tratamento específico com soro antiescorpiônico - SAE. A conduta orientada, inclusive o SAE foi iniciado após notificação, já decorridas 3h:38m após o acidente. O SAE foi administrado por via intravenosa, conforme prescrição da dose indicada (6 ampolas SAE) de acordo com a gravidade estimada do acidente. 
Orientado tratamento geral: limpeza e antissepsia no local da picada, visando prevenir infecção secundária; avaliar a necessidade de profilaxia antitetânica; tratamento sintomático (alívio da dor) e suporte vital. Realização de exames complementares - eletrocardiograma e radiografia de tórax; dosagem de glicemia, amilase, potássio, enzimas cardíacas (fração MB da creatino-fosfoquinase - CK-MB e troponina I), e hemograma, para acompanhamento da evolução clínica do caso.

Foi relatado que criança evoluiu com edema agudo de pulmão com a soroterapia, sendo necessário instituir ventilação mecânica. Solicitada transferência para unidade de terapia intensiva - UTI Pediátrica de hospital de referência regional e transferida seis horas após o acidente via SAMU Aeromédico.

Logo após admissão apresentou parada cardiorrespiratória - PCR, de difícil reanimação, sendo reorientada a complementação de mais duas ampolas de SAE e revisão de exames complementares. Instituição de drogas vasoativas. Repetidas PCR. Após mais de 30 horas do acidente, a criança evoluiu com choque cardiogênico e desfecho de óbito.

\section{Ocorrência 2 - Setembro}

Cinco anos, feminino, admitida em UPA do município de médio porte da região do Noroeste do Paraná, após trinta minutos de acidente individual por escorpião amarelo às 18h40min, "ao pisar em um pano no chão", com marca da picada em pé esquerdo. Criança estava em sua residência, localizada em região urbana do município de atendimento.

Ocorreram dois acidentes com o mesmo escorpião. A criança, imediatamente após a picada, chorou e sua mãe foi socorrê-la e "ao pegar o pano no chão" para ver o que tinha ocorrido também foi picada pelo mesmo escorpião "amarelo". Após o ocorrido, ambas foram levadas pela família a UPA, que capturou o escorpião.

A enfermeira da unidade realizou contato telefônico com o Centro de Informação e Assistência Toxicológica - CIAT de referência para a macrorregião Noroeste do Paraná 30min após a(s) ocorrência(s), e solicitou orientação e conduta para o(s) caso(s). A criança apresentava dor "moderada" e hiperemia no local da picada, sudorese, náuseas e vômito, agitação psicomotora. Desnutrição interrogada. Antes do contato com o CIAT foi medicada com Ondasetrona $2 \mathrm{mg}$, Bromoprida $5 \mathrm{mg}$, Dipirona sódica $500 \mathrm{mg} / \mathrm{ml} \mathrm{0,7} \mathrm{ml,} \mathrm{Hidrocortizona} 160 \mathrm{mg}$, SF 0,9\% $500 \mathrm{ml}$.

O tratamento indicado foi baseado em um presumível acidente escorpiônico por - Tityus serrulatus (Benchimol et al., 2017) e o caso foi classificado como grave. Foi orientado o tratamento específico, com seis ampolas de SAE, o tratamento geral e a realização de exames complementares, conforme relatado na Ocorrência 1. Às 20h21min, estagiária plantonista do CIAT registra na ficha Ocorrência Toxicológica / Animais que aguardava contato da UPA, pois o CIAT estava com problemas de acesso a unidade via telefone.

Duas horas após o acidente, o profissional de saúde da UPA informa ao CIAT que a criança estava apresentando rebaixamento do nível de consciência e em processo de transferência intra-hospitalar via SAMU - Suporte Avançado de Vida para unidade hospitalar de média complexidade do município, no momento do contato telefônico. Confirma o número de ampolas da SAE e cuidados para a soroterapia.

Quatro horas após o acidente, profissional da UTI Adulto do hospital fez novo contato remoto com o CIAT para solicitar informações necessárias para manejo clínico do caso, pois a transferência da criança para a UTI Pediátrica de hospital de referência regional ainda não havia sido efetivada, devido sua instabilidade clínica. Solicitou detalhamento sobre a administração do SAE - cuidados pré-soroterapia, da soroterapia via intravenosa e possíveis reações adversas imediatas e tardias.

A criança foi atendida na sala de estabilização do pronto socorro - PS, com agitação psicomotora, vômitos, dispneia e rebaixamento do nível de consciência + bradicardia; fornecido O2 com máscara, mas evoluiu com PCR, revertida após 30 min, e instalação de ventilação mecânica, com saída de grande quantidade de secreção tubo orotraqueal. Após contato com a UPA para enviar as ampolas para a SAE, foi realizado seis ampolas de soro antiescorpiônico em bomba de infusão contínua, com início da administração às 20h35min, duas horas após o acidente. 
Somente após a realização da SAE foi realizado contato com SAMU para verificação de vaga em UTI pediátrica e transporte, contudo a instabilidade clínica não possibilitou transporte. Repetição de PCR, com RCP mantida, revertida após 40min. Criança foi transferida para UTI Adulto do hospital, onde foram realizadas novas manobras de ressuscitação, sem sucesso, chegando ao desfecho de óbito cinco horas após o acidente.

\section{Discussão}

Os acidentes com escorpiões são ocorrências de notificação compulsória e devem ser notificados por comunicação telefônica aos CIAT, imediatamente após a entrada do acidentado no serviço de saúde, para orientação toxicológica e estadiamento do acidente para o tratamento (Santana \& Suchara; Souza et al., 2017), e posterior cadastro no Sistema de Informação de Agravos de Notificação (SINAN) (Souza et al., 2017; Brasil, 2017b). Os dados contidos nas notificações compõem as informações oficiais disponíveis sobre esses agravos à saúde e, a partir delas, é possível conhecer a amplitude e possibilitar reflexões que direcionam as ações de prevenção e assistência adequada aos acidentados (Brasil, 2017b; Bucaretchi et al., 2014).

A maioria dos acidentes com escorpiões ocorre no domicílio, como nos casos descritos no presente texto. Estes animais não atacam intencionalmente, mas habitualmente saem de seus esconderijos para buscar alimentos e o acidente ocorre no momento em que a pessoa afasta móveis, manipula roupas e objetos amontoados, calça sapatos, ou deixam a cama pela manhã, pois podem permanecer nas camas e nos lençóis durante a noite (Brasil, 2017a; Khattabi et al., 2011). Neste contexto, o horário - início da manhã e final do dia - e as circunstâncias dos acidentes descritos são compatíveis com as situações relatadas na literatura.

O local, a temporalidade e as circunstâncias de ocorrência dos acidentes confirmaram dados da literatura, e o encontro do escorpião no local do acidente e o transporte pré-hospitalar em caráter de urgência atuaram como facilitadores do diagnóstico precoce, porém a notificação do caso e solicitação de informação toxicológica das unidades de saúde de primeiro atendimento ao CIAT não foram satisfatória, com demora no contato telefônico após a admissão das crianças, o que geralmente determina o desfecho (Brasil, 2017b; Bucaretchi et al., 2014).

Diferenças entre classificação da gravidade e do desfecho clínico do acidente por escorpião estão associadas com características do animal, como a variabilidade de composição dos venenos e volume de peçonha inoculado; características da vítima, como faixa etária, massa corporal e sensibilidade do indivíduo à peçonha; e tempo transcorrido entre o momento do acidente e o socorro em serviços de saúde, com administração da SAE, se indicada (Carmo et al., 2019; Lima et al., 2016).

Em acidentes escorpiônicos, a inoculação da peçonha pode produzir sintomas locais, caracterizados principalmente por dor, de grau leve a de alta intensidade, mas também pode assumir repercussão sistêmica, que foram descritas por familiares das duas crianças como imediatos aos acidentes. O pronto reconhecimento da gravidade e estabelecimento de medidas clínicas pertinentes é fator relevante na resolução nos casos graves (Silva, Bernarde, \& Abreu, 2015; Araújo, Brites Neto, \& Gonçalves, 2016).

No estudo realizado por Carmo et al. (2019) a maior severidade dos casos foi associada com a faixa etária, com destaque de casos graves nos grupos de zero a 9 anos e com 60 anos ou mais. Nas crianças, o pior prognóstico pode ser explicado pela proporção de veneno inoculado em relação à menor superfície corpórea, e manifestações clínicas rapidamente desencadeadas e com maior intensidade associadas com a quantidade de veneno no plasma (Mesquita et al., 2015). Também, altas taxas de mortalidade por escorpionismo em crianças são justificadas pela baixa capacidade imunológica e por maior absorção do veneno pelo coração e outros órgãos (Cavazos et al., 2019).

Vinte por cento dos casos de acidentes com crianças com menos de sete anos são considerados moderados ou graves e podem levar ao óbito, embora normalmente estejam associados pela falta de diagnóstico oportuno e de qualidade, e à demora 
em considerar essa possibilidade diagnóstica (Pardal et al., 2014; Junglos et al., 2021). Nos casos em estudo, familiares informaram a presença e captura do escorpião no local do acidente, o que, segundo a literatura, confirma o diagnóstico clínico (Khattabi et al., 2011; Pardal et al., 2014).

A visualização do animal e o local da picada compatível com as histórias dos acidentes facilitou o diagnóstico clínico, e a não realização de medidas contraindicadas para primeiros socorros pelos familiares (Khattabi et al., 2011) foi benéfica para a evolução clínica. Os acidentes foram classificados corretamente (Brasil, 2017a; Araújo et al., 2016), pelas equipes de saúde do primeiro atendimento por meio do reconhecimento da gravidade do acidente e dos indicativos de gravidade clínica, observados nos casos em discussão, no entanto houve demora para o tratamento adequado e transferência das crianças para unidades de saúde de maior complexidade.

A maior pergunta clínica para o atendimento ao escorpionismo refere-se ao reconhecimento da gravidade no tempo zero do atendimento a vítimas pediátricas, associada à adequada condução clínica diante da classificação da gravidade. Os casos graves possuem indicação de suporte à vida em unidade de terapia intensiva. Hipoteticamente, espera-se que casos classificados corretamente e adequadamente conduzidos, com tempo reduzido em relação a admissão em unidades de atenção às urgências e soroterapia específica, tenham desfecho clínico mais adequado (Khattabi et al., 2011).

Logo após a picada a absorção do veneno começa rapidamente, alcançado a concentração máxima em 60 minutos. A presença de dor local, que pode ser discreta, restrita apenas ao ponto de inoculação do veneno, ou insuportável, em queimação ou agulhada, acompanhada ou não de parestesia, é o sintoma que se manifesta mais rapidamente, levando a vítima procurar o serviço de saúde na primeira hora. Entretanto, as manifestações sistêmicas podem aparecer precocemente, definindo maior gravidade clínica (Pinto, Pessoa, \& Silva, 2015).

A dor local decorre, provavelmente, de ação direta do veneno, através de proteínas neurotóxicas. A ausência da dor pode estar associada com a presença de outras manifestações mais evidentes do paciente, que a tornariam um aspecto menos destacado, pelo mesmo ou pelos profissionais assistentes, que não a registraram no prontuário. A associação entre sonolência observada no momento da admissão e a maior gravidade do caso denota a ação de proteínas do veneno no sistema nervoso central. Esta é uma manifestação pouco destacada na literatura, mas existem relatos de dismetria, ataxia de marcha e mioclonias, contraturas musculares e disartria (Cavazos et al., 2012).

Para o estadiamento de gravidade e manejo clínico dos casos, os CIAT tomam como base as diretrizes do Ministério da Saúde graves (Brasil, 2017a; Khattabi et al., 2011; Silva et al., 2015; Araújo et al., 2016), que orienta classificá-los em leves - sintomatologia local, como dor, edema, eritema e parestesia; ou moderados - manifestações sistêmicas transitórias, como náusea, sudorese, vômitos ocasionais, taquicardia, taquipneia, agitação psicomotora e hipertensão arterial leve; ou graves - com uma ou mais manifestações sistêmicas: sudorese profusa, vômitos incoercíveis, salivação excessiva, alternância de agitação com prostração, bradicardia, insuficiência cardíaca, edema pulmonar, choque, convulsões e sonolência (Brasil, 2017a; Brusamarello et al., 2019).

Nos casos moderados e graves podem ser detectados à chegada nos serviços de saúde hiperglicemia, hiperamilasemia, leucocitose, hipopotassemia e aumento das enzimas cardíacas (fração MB da creatino-fosfoquinase [CK-MB]) e troponina I, principalmente nos casos mais graves. As alterações mais encontradas no eletrocardiograma são taquicardia e bradicardia sinusal, extrassístoles ventriculares, inversão da onda T, supra e infradesnivelamento do segmento ST, presença de ondas Q, além de bloqueios da condução atrioventricular. Radiografia de tórax pode mostrar aumento da área cardíaca e edema agudo de pulmão (principalmente nas situações de infusão prévia de volume) (Cupo \& Custodio, 2018; Carmo et al., 2019).

No estudo de Carmo et al., (2019) as variáveis do exame inicial que estiveram associadas com maior gravidade foram a ausência de dor local, a presença de sonolência no momento da admissão e um tempo maior do que três horas decorrido entre a picada e a admissão hospitalar. As características clínicas dos casos ora estudados, tanto em relação às manifestações locais 
quanto sistêmicas, são semelhantes a estudos nacionais e internacionais (Cupo \& Custodio, 2018; Mesquita et al., 2015), com destaque para as manifestações neurológicas e cardiovasculares.

O tratamento sintomático inicial tem como prioridade o alívio da dor, realizado na maioria dos casos leves (90\%), e o tratamento específico, no caso o SAE ou, na falta deste, o soro antiaracnídico - SAAr, a saber: três ampolas nos casos moderados e seis ampolas nos graves. O soro antiveneno deve ser administrado precocemente, mas atua unicamente sobre o veneno circulante, portanto, o paciente deve ser monitorado continuamente durante 24 horas, recebendo tratamento de suporte de acordo com a clínica apresentada (Torrez et al., 2019; Pinto et al., 2015).

Casos moderados devem ser tratados com soroterapia específica em crianças abaixo de sete anos. Devido à possibilidade de redução da fração de ejeção cardíaca, a infusão de volume quando indicada, deverá ser realizada sob monitorização rigorosa, devido ao risco de evolução para choque cardiogênico (Cupo et al., 2018). Considerando o protocolo clínico brasileiro (Brasil, 2017a) e os protocolos internacionais (Brusamarello et al., 2019), como a comunicação das unidades de saúde com o CIAT não foi realizada de forma satisfatória e imunobiológico para SAE não foi acessado imediatamente, o tempo de administração da SAE não foi adequado a estes protocolos.

Além de atividades educativas sobre os hábitos de vida dos escorpiões e da necessidade de orientação para a população em geral a respeito da busca imediata ao serviço de saúde de atenção à urgência, para que casos fatais sejam evitados, faz-se necessária maior descentralização na distribuição do soro específico, com o cumprimento adequado de medidas de rede de frio (Brasil, 2017a; Brusamarello et al., 2019), uma vez que o intervalo de tempo entre o acidente e o estabelecimento do tratamento tem associação direta com o agravamento e prognóstico do acidente (Yin, 2015).

Todo profissional de saúde que atua em pronto-socorro precisa estar apto a reconhecer a gravidade do problema e entrar em contato com algum dos 31 Centros de Assistência Toxicológica do país, garantindo que o paciente chegue rápido a um local que tenha o antiveneno (Yin, 2015). Estudo que avaliou a evolução letal do escorpionismo em crianças e adolescentes apontou que, para cada hora de aumento no tempo até o primeiro atendimento, há um acréscimo de 9\% na chance de evoluir para óbito, e que esta chance aumenta para $13 \%$ a cada ano diminuído na idade da vítima. Desse modo, a urgência no atendimento aos casos de escorpionismo deve ser considerada, uma vez que um possível quadro clínico sistêmico pode se estabelecer dentro de alguns minutos a poucas horas (Çağlar et al., 2015).

Como limitação do estudo destaca-se a utilização estudo de caso, pela impossibilidade de generalização dos resultados e suas conclusões serem específicas para os casos estudados. No entanto, o método empregado possibilita conhecer em profundidade aspectos de um determinado caso e pode ser utilizado por pesquisadores para indicar a prática de saúde no contexto em que ela é desenvolvida.

Na análise dos presentes casos apontou-se a eficiência de organização e práticas de saúde, como precocidade do acesso à unidade de saúde e identificação dos sinais e sintomas, mas também aspectos negativos, como a comunicação deficiente com o CIAT de referência macrorregional, retardando o tempo entre o acidente e a informação toxicológica eficiente, e a aplicação da soroterapia antiescorpiônica acima do preconizado, que foi determinante para desfecho desfavorável dos casos.

\section{Considerações Finais}

As lições apreendidas dos casos se referem ao alerta para gravidade dos casos de escorpionismo em crianças e a indicação do uso precoce da SAE ou SAAr, a necessidade de utilização de leitos de terapia intensiva para tratamento de suporte de acordo com a clínica apresentada e estrutura e equipes de saúde capacitadas para atendimento de alta complexidade, pois os acidentes escorpiônicos são emergências cotidianas de saúde na década de 2020.

Os profissionais de saúde devem estar capacitados para o diagnóstico precoce - reconhecimento de casos leves, moderados e graves, e busca de informação com evidência clínica nos CIAT, para confirmação do estadiamento clínico e 
tratamento adequado aos casos. A atualização de condutas de diagnóstico e tratamento dos acidentados por escorpiões é imprescindível, pois frequentemente os profissionais de saúde não recebem informações desta natureza durante os cursos de graduação ou no decorrer da atividade profissional.

Sugere-se investigações para além dos estudos de caso, de caráter analítico e longitudinal para avaliar as práticas de saúde voltadas ao escorpionismo, para confirmação e generalização dos achados nos presentes casos.

\section{Referências}

Araújo, M. V., Brites Neto, J., \& Gonçalves., M. E. C. N. (2016). Análise epidemiológica e distribuição espacial e temporal dos acidentes por escorpiões na cidade de Americana, São Paulo, Brasil. BEPA, Bol epidemiol paul,13(156), 1-18.

Benchimol, J. L., \& Sá M. R. A. L. (2007). Outros estudos em zoologia: Editora FIOCRUZ, 3 (4), 584.

Bochner, R, Fiszon, J. T., \& Machado, C. (2014). A Profile of Snake Bites in Brazil, 2001 to 2012. J Clin Toxicol, 4(3), 1-7.

Bucaretchi, F, Fernandes, L. C., Fernandes C. B., Branco, M. M., Prado C. C., Vieira, R. J., Capitani, E. M. D., \& Hyslop, S. (2014). Clinical consequences of Tityus bahiensis and Tityus serrulatus scorpion stings in the region of Campinas Southeastern Brazil. Toxicon, 89.17-25.

Brusamarello, T., Silva, S. O., \& Machado, E. M. (2019). Cuidado de enfermagem a familiares de pacientes em unidade de terapia intensiva: revisão integrativa. Saude e pesquisa, 12(3), 629-638.

Cavazos, M. E. O., Garza, C. R., Guajardo-Rodríguez, G., Hernández-Montelongo, B. A., \& Montes-Tapia F. D. (2002). Snake bites in pediatric patients, a current view. Complementary Pediatrics, 7:123-136

Cardoso, J. L. C., França, F. O. S., Wen, F. H., Málaque, C. M. S., \& Haddad, V. Jr. (2003). Venomous animals in brazil: biology, clinic and therapeutics of envenomations. Rev Inst Med Trop, 45 (6), 338.

Carmo, E. A., Nery, A. A., Pereira, R., Rios, M. A., \& Casotti, C. A. (2019). Fatores associados à gravidade do envenenamento por escorpiões. Texto Contexto Enferm. 28:e20170561.

Cupo, P., \& Custodio, V. I. C. (2018). Acidente escorpiônico na sala de urgência. Revista Qualidade HC.1-3.

Khattabi, A., Soulaymani-Bencheikh, R., Achour, S., \& Salmi, L. R. (2011). Classification of clinical consequences of scorpion stings: consensus development. Trans R Soc Trop Med Hyg, 105 (7), 364-9.

Lima, E. C, Soares, G. R. A., \& Pinho, L. (2016). Caracterização de crianças hospitalizadas vítimas de acidentes por animais peçonhentos. Rev enferm UFSM, $6(2), 206-213$.

Mesquita, F. N., Nunes, M. A., Santana, V. R., Machado Neto, J., Almeida, K. B., \& Lima, S. O. (2015). Acidentes escorpiônicos no Estado do Sergipe - Brasil. Rev Fac Ciênc Méd Sorocaba, 17 (1),15-20.

Ministério da Saúde. (2017a) Secretaria de Vigilância em Saúde. Acidentes por animais peçonhentos: análise dos dados epidemiológicos de 2000-2017: MS. http://portalarquivos2.saude.gov.br/images/pdf/2018/junho/25/1-Casos-Escorpionismo-2000-2017.pdf

Ministério da Saúde. (2017b). Sistema de Informação de Agravos de Notificação: MS.http://portalsinan.saude.gov.br/dados-epidemiologicos-sinan.

Junglos, P., Shibukawa, B. M. C., Evangelista, F. F., Merino, M. de F. G. L., Higarashi, I. H., Oliveira, M. L. F de., \& Furtado, M. D. (2021). Escorpionismo em crianças e adolescentes: dados de uma unidade sentinela. Pesquisa, Sociedade e Desenvolvimento ,10 (1), e54610112079.

Pereira, A. S., Shitsuka, D. M., Parreira, F. J., \& Shitsuka, R. (2018). Metodologia da pesquisa cientifica. UAB/NTE/UFSM. https://repositorio.ufsm.br/bitstream/handle/1/15824/Lic_Computacao_Metodologia-Pesquisa-Cientifica.pdf?sequence=1

Pardal, P. P. O., Ishikawa, E. A. Y., Vieira, J. L. F., Coelho, J. S., Dórea, R. C. C., Abati, P. A. M., Quiroga, M. M. M., \& Chalkidis, H, M. (2014). Clinical aspects of envenomation caused by Tityus obscurus (Gervais, 1843) in two distinct regions of Para state, Brazilian Amazon basin: a prospective case series. Journal of Venomous Animals and Toxins including Tropical. Diseases. 20:3.

Pinto, G. S. F. G., Pessoa, A. M., \& Silva, S. J. Jr. (2015). Acidentes com escorpiões nas capitais brasileiras entre 2007 e 2014. Estudos Vida e Saúde, 42(4), 529546.

Santana, V. T. P., \& Suchara, E. A. (2015). Epidemiologia dos acidentes com animais peçonhentos registrados em Nova Xavantina - MT. Rev epidemiol controle infecç. 5(3), 141-146.

Secretaria de Estado da Saúde do Paraná (SESA). (2016). Plano Estadual de Saúde Paraná 2016-2019. Brasil. http://www.conass.org.br/pdf/planos-estaduaisde-saude/PR_PlanoEstadualSaude2016MioloAlt.pdf.

Silva, A. M., Bernarde, P. S., \& Abreu, L. C. (2015). Acidentes com animais peçonhentos no Brasil por sexo e idade. J Hum Growth Dev, $25(1)$, 54-62.

Souza, L. M., Pinto, R. N. L., Feitosa, D. T., \& Silva, N. J, Jr (2017). Estudo retrospectivo do escorpionismo no Estado de Goiás (2003-2012). Estudos Vida e Saúde, 44, 100-14. 
Research, Society and Development, v. 10, n. 2, e24110212457, 2021

(CC BY 4.0) | ISSN 2525-3409 | DOI: http://dx.doi.org/10.33448/rsd-v10i2.12457

Torrez, P. P. Q., Dourado, F. S., Bertani, R., Cupo, P., \& França, F. O. S. (2019). Scorpionism in Brazil: exponential growth of accidents and deaths from scorpion stings. Rev Soc Bras Med Trop, 52:e20180350.

World Health Organization (WHO). (2007). Rabies and Envenomings: a neglected public health issue: Report of a Consultative Meeting. https://apps.who.int/iris/handle/10665/43858.

Yin, R. K. (2015). Estudo de caso: planejamento e métodos. (5a ed.), Bookman.

Çağlar, A., Köse, H., Babayiğit, A., Öner, T., \& Duman, M. (2015). Predictive factors for determining the clinical severity of pediatric scorpion envenomation cases in Southeastern Turkey. Wilderness Environ Med. 26, 451-8. 